request a copy. In fact, when an author gets his or her work published in a scientific journal, the journal publisher often provides the author with a number of paper copies for this purpose. Since most scientists are proud of their efforts, they usually welcome requests for copies of their papers, despite the nuisance involved. Indeed, many scientists quickly come to recognize that responding to reprint requests promptly can only help one's standing in the scientific community (as long as your work is good in the first place).

This reprint system has existed for many years, and is particularly useful to scientists without access to a quality scientific library, such as scientists in some parts of Central America or Eastern Europe.

One drawback of this system is that many authors do not respond to reprint requests either because they did not initially order copies of their article (they can be expensive) or because they sometimes run out of copies. There are also administrative and mailing expenses to contend with.

Note also that while the author may send off an allocation of reprints as he or she sees fit, technically the author may not make additional copies using a photocopier without following applicable copyright regulations, such as the requirement that a specified sum of money be sent to a copyright clearance centre for each copy made. (Such fees are usually in the order of a dollar or more per copy made.) This situation exists because the journal, not the author, is the usual owner of the intellectual property in question.

It should also be mentioned that the occasional practice of scientists placing a copy of one of their published journal articles on the web, while a great convenience to other scientists, likely goes against the terms of any copyright assignment agreement signed by the author. (However, many journals would likely not take action on such matters unless they felt threatened in some way. In particular, many journals see a value to making their abstracts available via the web, since such a policy would be expected increase demand for the full articles that they sell.)

These issues suggest that there is a need to explore new means by which reprints might be distributed. The purpose of this commentary, then, is to consider potential electronic reprint systems that might offer improvements on how things are now done.

\section{Images of a New Paradigm}

Developments in computers and communication technology now offer us a new ways to distribute sci- entific reprints. Consider the advantages and draw backs of a hypothetical new paradigm that such technology supports.

In the new paradigm authors could still order paper reprints or make copies by paying the required fees to a clearance center. However, in addition, reprints would also be available electronically as "e-prints" from the journal's web site under one of three business revenue models:

1. The author agrees to pay the publisher either a fixed fee, a fee for each copy downloaded from the site, or a combination of these. [This is akin to the "page charge" model used by some journals.]

2. The reprint requester gets access to the reprint file upon making an e-payment or by providing credit card information. [E-commerce / news stand model].

3. An advertiser agrees to pay the publisher either a fixed fee, a fee for each copy downloaded from the site, or a combination of these. [Radio and TV model].

In some cases the publisher may also agree to an arrangement providing for a reduction in copy price once sufficient electronic reprints have been sold to cover expenses and profits.

\section{Portable Data Format}

One practical issue concerns the document format to be used to distribute electronic reprints. In my view, the document format most likely to succeed for such an initiative is Adobe's popular "pdf" format, (Portable Data Format) an electronic document format already used extensively for the distribution of information within government and industry. The Portable Data Format supports text, tables, columns, images and even multimedia features such as sound files, video clips and hyperlinks. While Microsoft Word, Word Perfect, Postscript, RTF, HTML and SGML document formats could (at least theoretically) also be used for electronically publishing reprints, in my opinion the technical features and ease of use of the Adobe system make it a clear winner for an application such as making electronic reprints. In particular, the Adobe publishing system (known as Adobe Acrobat [Release 4.0]) is very easy to use since it simply configures as a printer under Windows, while the required viewer software to display the pdf files may be freely downloaded from http://www.abobe.com Of special interest to publishers using the Adobe elec- 
tronic document system is the ability to generate files that may be viewed but cannot be printed (at least not easily). That way one cannot print out a copy for mass distribution via photocopier (although the pdf file can still be copied and e-mailed). For example, this restriction was chosen when the American Society of Anesthesiologists published the 1998 ASA Refresher Course Lectures on CD-ROM.

My vision, then, is that an e-print would usually consist of a cover sheet, the paper itself, and finally an advertisement. The cover sheet would contain the journal logo, title and author information, and perhaps even hyperlinks that would launch a web browser that would lead one to the journal web page or the sponsoring society web page. The advertisement would either be for the journal itself, including a sample order form, or for products and services offered by pharmaceutical and other companies. Hyperlinks on this page would likely also be implemented.

In summary, in the new paradigm copyright for eprint publications would remain with the journal or publisher. Copies of the e-print would be made available at the journals web site, and the journal would keep a record of the number of downloads so as to charge fees according to one of the business revenue models mentioned above.

D. John Doyle MD PHD FRCPC

Toronto, Ontario 